\title{
A Discrete Element Contact Model for Fatigue Crack Growth Analysis
}

\author{
L. MA ${ }^{* \dagger}$, G. Koval ${ }^{\dagger}$, C. Chazallon ${ }^{\dagger}$ and Y.Descantes ${ }^{\sharp}$ \\ ${ }^{*}$ Université de Strasbourg, INSA de Strasbourg, \\ CNRS, ICube, UMR 7357, F-67000, Strasbourg France \\ Email:lei.ma@insa-strasbourg.fr \\ georg.koval@insa-strasbourg.fr \\ cyrille.chazallon@insa-strasbourg.fr \\ ¥Université Gustave Eiffel, Ifsttar - Nantes, \\ Route de Bouaye - CS 5004, F-44344 Bouguenais Cedex France \\ Email: yannick.descantes@univ-eiffel.fr
}

\begin{abstract}
The Discrete Element Method (DEM) is very useful to describe the heterogeneous microstructure of geomaterials at particle scale. Fatigue loading induces multi-crack growth in materials such as cement and asphalt concretes, rocks, etc. However, the rate of fatigue crack growth is usually below the smallest particle size, which complexifies the description of a continuous loss of stiffness. In the present work, a new contact model which relates the loss of stiffness of a contact to any scale of crack growth is proposed. This relation is obtained with the theoretical release of energy at a crack tip and the energy released due to contact stiffness degradation. Thus, a Paris law like criterion is adapted to characterize the crack growth rate. The model is first validated for theoretical pre-cracked plates under cyclic loading. Then, the analysis is extended to experimental results comparison. Finally, the consistency of these preliminary results is associated to more complex and practical perspectives of the proposed numerical approach.
\end{abstract}

